\title{
Differential Geometry: \\ Theory and Applications
}




\title{
Series in contemporary Applied Mathematics CAM
}

\author{
Honorary Editor: Chao-Hao Gu (Fudan University) \\ Editors: P. G. Ciarlet (City University of Hong Kong), \\ Ta-Tsien Li (Fudan University)
}

1. Mathematical Finance — Theory and Practice

(Eds. Yong Jiongmin, Rama Cont)

2. New Advances in Computational Fluid Dynamics - Theory, Methods and Applications

(Eds. F. Dubois, Wu Huamo)

3. Actuarial Science — Theory and Practice

(Eds. Hanji Shang, Alain Tosseti)

4. Mathematical Problems in Environmental Science and Engineering

(Eds. Alexandre Ern, Liu Weiping)

5. Ginzburg-Landau Vortices

(Eds. Haïm Brezis, Ta-Tsien Li)

6. Frontiers and Prospects of Contemporary Applied Mathmetics

(Eds. Ta-Tsien Li, Pingwen Zhang)

7. Mathematical Methods for Surface and Subsurface Hydrosystems

(Eds. Deguan Wang, Christian Duquennoi, Alexandre Ern)

8. Some Topics in Industrial and Applied Mathematics

(Eds. Rolf Jeltsch, Ta-Tsien Li, Ian Hugh Sloan)

9. Differential Geometry: Theory and Applications

(Eds. Philippe G. Ciarlet, Ta-Tsien Li) 
Series in Contemporary Applied Mathematics CAM 9

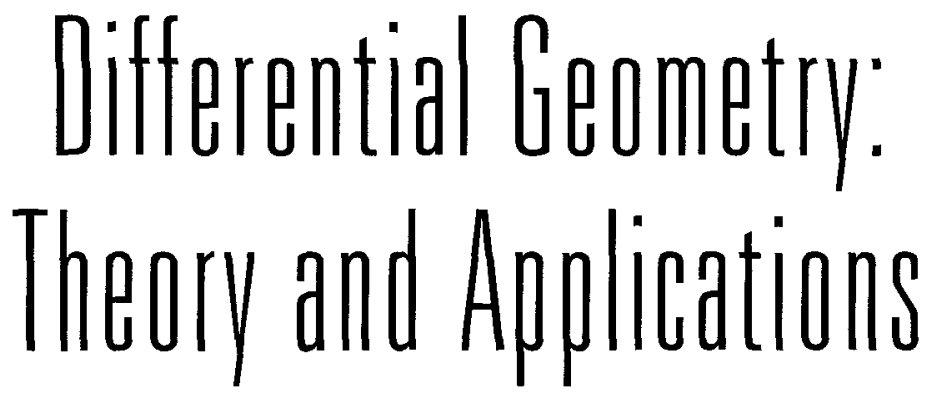

editors

\section{Philippe G Ciarlet}

City University of Hong Kong, China

Ta-Tsien Li

Fudan University, China

Higher Education Press

19 World Scientific 


\section{Philippe G. Ciarlet}

Department of Mathematics

City University of Hong Kong

83 Tat Chee Avenue

Kowloon, Hong Kong

China

\section{Ta-Tsien Li}

School of Mathematical Sciences

Fudan University

220, Handan Road

Shanghai, 200433

China

Editorial Assistants: Zhou Chun-Lian

\section{图书在版编目 (CIP) 数据}

微分几何: 理论与应用 = Differential Geometry:

Theory and Applications: 英文 / (法) 希阿雷 (Ciarlet, P. G.), 李大潜主编. 一北京: 高等教育出版社, 2007.11

(现代应用数学丛书)

ISBN 978-7-04-022283-8

I.微… II.(1)希…(2)李... III.微分几何一英文 IV. 0186.1

中国版本图书馆 CIP 数据核字 (2007) 第 163222 号

Copyright (c) 2008 by

\section{Higher Education Press}

4 Dewai Dajie, Beijing 100011, P. R. China, and

\section{World Scientific Publishing Co Pte Ltd}

5 Toh Tuch Link, Singapore 596224

All rights reserved. No part of this book may be reproduced or transmitted in any form or by any means, electronic or mechanical, including photocopying, recording or by any information storage and retrieval system, without permission in writing from the Publisher.

\section{ISBN 978-7-04-022283-8}

Printed in P. R. China 


\section{Preface}

The ISFMA-CIMPA School on "Differential Geometry: Theory and Applications" was held on 07 August - 18 August 2006, in the building of the Chinese-French Institute for Applied Mathematics (ISFMA), Fudan University, Shanghai, China. This school was jointly organized by the ISFMA and the CIMPA (International Centre for Pure and Applied Mathematics), Nice, France. About sixty participants from China, Hong Kong, France, Cambodia, India, Iran, Pakistan, Philippines, Romania, Russia, Sri-Lanka, Thailand, Turkey, Uzbekistan and Vietnam attended this highly successful event.

The first objective of this school was to lay down in a self-contained and accessible manner the basic notions of differential geometry, such as the metric tensor, the Riemann curvature tensor, the fundamental forms of a surface, covariant derivatives, and the fundamental theorem of surface theory etc. Although this field is with good reasons often considered as a "classical" one, it has been recently "rejuvenated", thanks to the manifold applications where it plays an essential role.

The second objective of this school was to present some of these applications, such as the theory of linearly and nonlinearly elastic shells, the implementation of numerical methods for shells, and mesh generation in finite element methods.

To fulfill these objectives, four series of lectures, each series comprising ten 50min-lectures, were delivered under the following titles: "Introduction to differential geometry", "Introduction to shell theory", "A differential geometry approach to mesh generation", and "Numerical methods for shells". This volume gathers the materials covered in these lectures. As such, this volume should be very useful to graduate students and researchers in pure and applied mathematics.

The organizers take pleasure in thanking the various organizations for their generous support: The ISFMA, the CIMPA, the French Embassy in Beijing, the Consulate General of France in Shanghai, the National Natural Science Foundation of China, Fudan University, Higher Education Press and World Scientific. Finally, our special thanks are due to Mrs. Zhou Chun-Lian for her patient and effective work in editing this book. 
This page intentionally left blank 


\section{Contents}

\section{Preface}

Philippe G. Ciarlet: An Introduction to Differential

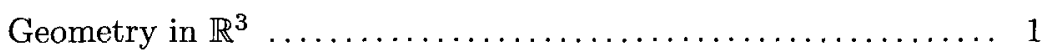

Philippe G. Ciarlet, Cristinel Mardare: An Introduction to Shell Theory $\ldots \ldots \ldots \ldots \ldots \ldots \ldots \ldots \ldots \ldots \ldots \ldots \ldots$

Dominique Chapelle: Some New Results and Current

Challenges in the Finite Element Analysis of Shells ........ 185

Pascal Frey: A Differential Geometry Approach to

Mesh Generation .............................. 222 